\title{
ENSAIOS
}

\section{INFLUÊNCIA DAS TECNOLOGIAS NA RETENÇÃO DE SÓCIOS EM GINÁSIOS: REVISÃO SISTEMÁTICA}

\author{
THE INFLUENCE OF TECHNOLOGIES ON MEMBERS' RETENTION BY \\ GYMS: A SYSTEMATIC REVIEW C己
}

\section{INFLUENCIA DE LAS TECNOLOGÍAS EN LA RETENCIÓN DE SOCIOS EN GIMNASIOS: REVISIÓN SISTEMÁTICA Cृ}

doi' https://doi.org/10.22456/1982-8918.100316

\section{Delena Ferreira Barbosa* <helena.barbosa@ipbeja.pt> \\ Jerónimo García-Fernandez** <jeronimo@us.es> \\ Gabriel Cepeda Carrión** <gabi@us.es>}

\author{
*Instituto Politécnico de Beja. Beja, Portugal. \\ **Universidade de Sevilha. Sevilha, Andalucia, Espanha.
}

Resumo: O objetivo desta revisão sistemática é identificar a influência das redes sociais e tecnologias na retenção de clientes em ginásios. A pesquisa foi efetuada em quatro bases de dados online, de 2011 a 2019. Através do método PRISMA (MOHER et al., 2009), foram selecionados dez artigos. Os resultados evidenciaram que as redes sociais e o uso de tecnologias são fundamentais no processo de retenção. Após a análise dos dez artigos, foram também identificadas e analisadas as variáveis características pessoais dos sócios, frequência e tempo de utilização e qualidade do serviço e satisfação, como influenciadoras da retenção de clientes. Resumindo, este estudo fez uma revisão dos artigos que estudam o impacto das tecnologias e redes sociais na retenção de clientes em ginásios e ajudou a identificar outros fatores que incidem na retenção clientes, agrupando-os em duas dimensões, associadas à empresa e ao cliente.

Palavras chave: Rede Social. Tecnologia. Comportamento. Revisão Sistemática.
Recebido em: 06-02-2020 Aprovado em: 23-07-2020 Publicado em: 19-09-2020

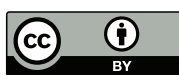

Este é um artigo publicado sob a licença Creative Commons Atribuição 4.0 Internacional (CC BY 4.0). eISSN: $1982-8918$ 


\section{INTRODUÇÃO}

O conceito de retenção em ginásios refere-se à retenção de sócios e é considerado fundamental para a sua rentabilidade (FERRAND; ROBINSON; VALETTEFLORENCE, 2010). De acordo com Pedragosa (2012) existem vários sinónimos de retenção na literatura, tais como fidelização ou lealdade. A retenção é entendida como a tendência de recompra do produto, ou seja, de renovar a mensalidade para continuar como sócio do ginásio (BODET, 2012; HALLOWELL, 1996; OLIVER, 1999).

Um problema com que os gestores dos ginásios se deparam diariamente é a retenção dos seus sócios. Para Talley (2008), não existe uma solução simples para resolver o problema, mas existem várias estratégias e processos que se podem adotar. Revela-se, então, de extrema importância compreender as variáveis que afetam o comportamento de retenção.

A internet, as tecnologias móveis, os big data e outros fenómenos tecnológicos estão a causar mudanças nas empresas e na sociedade (BREM; VOIGT, 2009). A internet mudou a indústria, e o digital assumiu importância em todas as atividades económicas. Nesse sentido, essa evolução exige gerentes capazes de ajudar as empresas a superar os desafios (VASCONCELOS; KIMBLE; ROCHA, 2016). O mercado tornou-se, de modo geral, um mercado de personalização, em que a qualidade, o preço e a velocidade de entrega são enfatizados (SOUSA; ROCHA, 2019). Essa mudança trouxe novos e emergentes segmentos de clientes, diversidade cultural num mercado global, volatilidade do mercado, aumento das expectativas dos clientes em relação à qualidade dos produtos e serviços e impacto da internet no negócio principal da empresa (AKERMAN; GAARDER; MOGSTAD, 2015).

Nas empresas seguradoras, por exemplo, já existem estudos que comprovam que a utilização da tecnologia CRM (Customer Relationship Management) permite desenvolver estratégias de marketing eficientes para reter os clientes, aumentando, assim, a rentabilidade destas empresas (MADHOVI; DHLIWAYO, 2017; MATIŞ; LIVIU, 2014). Na indústria hoteleira, de acordo com alguns estudos, as tecnologias de informação revelam-se também um fator determinante para reduzir custos e aumentar a rentabilidade, contribuindo para a satisfação e lealdade dos clientes (HASSAN; HUSSAIN; RAHMAN, 2013; KARIMI; SOMERS; GUPTA, 2001). Na indústria da restauração, a tecnologia tem impulsionado as compras online, permitindo aos restaurantes não só desenvolver o seu mercado (NG; WONG; CHONG, 2017; YEO; GOH; REZAEI, 2017), mas também aumentar a produtividade, a precisão das encomendas e estabelecer uma relação com os clientes (KIMES, 2011). Com o aumento do uso dos telemóveis, os bancos encontraram também uma grande oportunidade de melhorar a retenção de clientes (SHAIKH; KARJALUOTO, 2015). Para Alonso-dos-Santos, Soto-Fuentes e Valderrama-Palma (2020), a utilização do serviço mobile banking tem uma relação forte e direta com a fidelidade.

Particularmente no setor desportivo, o crescimento do uso das tecnologias permitiu facilitar e melhorar a adesão à prática desportiva e deve ser entendido como um meio que influencia essa mesma prática (VALCARCE; DÍEZ-VALGO, 2018). Já existem estudos que indicam que a adesão é maior nos indivíduos que utilizam 
aplicações móveis (DU et al., 2016; VOTH; OELKE; JUNG, 2016). No entanto, é importante que a sua utilização seja empregada para facilitar a retenção dos sócios, para além de garantir a prática desportiva. Com esse objetivo, começam a surgir empresas a investir nas aplicações de fitness (TU; HSIEH; FENG, 2018).

Quanto à utilização das redes sociais, de acordo com Richter e Kazley (2020), estas são utilizadas por alguns hospitais para envolver os consumidores e para melhorar a educação e informação em questões relacionadas com a saúde. De acordo com os mesmos autores, os hospitais com uma página no Facebook e com mais "gostos", tinham mais pacientes a recomendar o hospital e um maior índice de satisfação geral. Outro estudo realizado num hospital verificou que as redes sociais influenciam a fidelização dos clientes (SANTOSO; DEWI, 2020). Gamboa e Gonçalves (2014) verificaram também o papel das redes sociais na fidelização de clientes, no setor do retalho. De acordo com este estudo, os fãs da marca Zara no Facebook tinham um nível de confiança mais elevado, estavam mais satisfeitos e, consequentemente, expressavam mais lealdade à marca. No seu estudo realizado na indústria das pizzas, $\mathrm{He}$, Zha e Li (2013) concluem que as redes sociais desempenham um papel importante na sustentação de uma relação positiva com os clientes, revelando-se indispensáveis para atrair novos clientes, melhorar a satisfação dos utilizadores, aumentar as vendas e receitas, fidelizar e, consequentemente, construir uma boa reputação da marca.

No que diz respeito às redes sociais no contexto desportivo, segundo GarcíaFernández et al. (2017), estas promovem a interação entre a empresa e o cliente, levando a um maior envolvimento e compromisso. Isso cria mais referências ao produto e à marca, criando experiências e contribuindo para o processo de inovação e retenção (BOWDEN, 2009; BRODIE et al., 2011; PRAHALAD; RAMASWAMY, 2004).

García-Fernández et al. (2017) verificaram com o seu estudo que existe uma relação positiva entre o número de seguidores das redes sociais e a receita dos ginásios, devendo fazer parte das estratégias de marketing dessas empresas. As redes sociais levam a que os seguidores aumentem a sua afinidade com o ginásio. A tecnologia faz parte do valor percebido pelo cliente, diretamente relacionado à qualidade percebida e, portanto, também à satisfação e por sua vez à retenção, já que a satisfação dos clientes e a qualidade de serviço estão ambas relacionadas indiretamente com a retenção (GARCÍA-FERNÁNDEZ et al., 2019).

O mercado do fitness encontra-se saturado, levando os ginásios a procurar métodos que fidelizem e atraiam novos clientes. $O$ uso das tecnologias revela-se cada vez mais uma necessidade para os centros de fitness, bem como o uso das redes sociais, mas a literatura não é unânime em relação ao impacto da sua utilização na retenção do cliente. Assim, o objetivo da presente revisão sistemática é identificar a influência das redes sociais e tecnologias na retenção de clientes em centros de fitness.

\section{MÉTODO}

O estudo foi desenvolvido seguindo a estrutura e recomendação de outras revisões sistemáticas (CASTRO-PINERO et al., 2010; RUIZ-ARIZA et al., 2017; ZANATTA et al., 2018) e o tratamento utilizado pelas orientações do PRISMA 
(Preferred Reporting Items for Systematic Reviews and Meta-Analysis) para relatórios e estudos. A recomendação PRISMA define-se como um conjunto de itens baseados em evidências, para realizar revisões sistemáticas e meta-análises. Consiste numa lista de verificação e num diagrama de fluxo. O PRISMA é composto por uma checklist de 27 itens, que ajudam o autor a certificar-se de que analisou todos os aspetos da revisão sistemática. Inclui também um fluxograma com o número total de referências encontradas, número de artigos que foram excluídos nas várias fases e número de artigos chegaram à fase final. O objetivo do PRISMA é ajudar os autores a melhorarem o relato de revisões sistemáticas e meta-análises (MOHER et al., 2009).

\subsection{SELEÇÃO DA LITERATURA}

Durante o mês de dezembro de 2019 foi realizada uma pesquisa abrangente de quatro bases de dados (Web of Science, Scopus, EBSCO e PubMed), de janeiro de 2011 a dezembro de 2019. As principais categorias de termos de pesquisa em inglês foram: 1) "retention" (fidelity, loyalty, adherence), 2) "health fitness club" (fitness center, health club, gymnasium), 3) "technology" (social networks, mobile phone, smartphone, app, facebook, twitter, Instagram, gamification). O Quadro 1 apresenta os principais termos utilizados na pesquisa por categoria.

Quadro 1 - Estratégia de pesquisa nas bases de dados.

\begin{tabular}{|c|c|c|c|c|}
\hline $\begin{array}{c}\text { Base de } \\
\text { dados }\end{array}$ & Estratégia de Pesquisa & Limites & $\begin{array}{l}\text { Total de } \\
\text { artigos } \\
\text { obtidos }\end{array}$ & $\begin{array}{c}\text { Total de } \\
\text { artigos } \\
\text { selecionados }\end{array}$ \\
\hline $\begin{array}{l}\text { Web of } \\
\text { Science }\end{array}$ & $\begin{array}{l}\text { (TS=( retention OR fidelity OR loyalty } \\
\text { OR adherence) AND TS=(health } \\
\text { fitness club* OR fitness center* OR } \\
\text { health club* OR gymnasium ) AND } \\
T S=(\text { technology OR social networks } \\
\text { OR mobile phone OR smartphone } \\
\text { OR app* OR facebook OR twitter OR } \\
\text { instagram OR gamification)) }\end{array}$ & $\begin{array}{l}\text { Data de publicação: } \\
\text { Após 2011; } \\
\text { Tipo de documento: } \\
\text { Article ou Review; } \\
\text { Idioma: Português, } \\
\text { Inglês e Espanhol. } \\
\text { Open Acess }\end{array}$ & 97 & 2 \\
\hline Scopus & $\begin{array}{l}\text { (retention OR fidelity OR loyalty } \\
\text { OR adherence) AND (health AND } \\
\text { fitness AND club* OR fitness AND } \\
\text { center* OR health AND club* OR } \\
\text { gymnasium) AND (technology OR } \\
\text { social AND networks OR mobile AND } \\
\text { phone OR smartphone OR app* OR } \\
\text { facebook OR twitter OR instagram } \\
\text { OR gamification) }\end{array}$ & $\begin{array}{l}\text { Data de publicação: } \\
\text { Após 2011; } \\
\text { Tipo de fonte: } \\
\text { Journals } \\
\text { Tipo de documento: } \\
\text { Article, Review } \\
\text { Idioma: Português, } \\
\text { Inglês e Espanhol. } \\
\text { Open Acess }\end{array}$ & 56 & 2 \\
\hline EBSCO & $\begin{array}{l}\text { ((retention OR fidelity OR loyalty OR } \\
\text { adherence ) AND ( health fitness club* } \\
\text { OR fitness center* OR health club* OR } \\
\text { gymnasium ) AND ( technology OR } \\
\text { social networks OR mobile phone OR } \\
\text { smartphone OR app* OR facebook OR } \\
\text { twitter OR instagram OR gamification) }\end{array}$ & $\begin{array}{l}\text { Data de publicação: } \\
\text { de 01/01/2011 a } \\
\text { 31/12/2019 } \\
\text { Tipo de fonte: } \\
\text { Revistas Científicas } \\
\text { (analisadas por } \\
\text { pares) } \\
\text { Idioma: Português, } \\
\text { Inglês e Espanhol. } \\
\text { Texto Integral }\end{array}$ & 303 & 6 \\
\hline
\end{tabular}


Continuação do quadro 1.

\begin{tabular}{|c|c|c|c|c|}
\hline PubMed & $\begin{array}{l}\text { (((retention OR fidelity OR loyalty OR } \\
\text { adherence)) AND (health fitness club* } \\
\text { OR fitness center* OR health club* } \\
\text { OR gymnasium)) AND (retention OR } \\
\text { fidelity OR loyalty OR adherence) } \\
\text { AND (health AND fitness AND club* } \\
\text { OR fitness AND center* OR health } \\
\text { AND club* OR gymnasium) AND } \\
\text { (technology OR social AND networks } \\
\text { OR mobile AND phone OR smartphone } \\
\text { OR app* OR facebook OR twitter OR } \\
\text { instagram OR gamification) }\end{array}$ & $\begin{array}{l}\text { Data de publicação: } \\
\text { Após 2011; } \\
\text { Idioma: Português, } \\
\text { Inglês e Espanhol. } \\
\text { Free Full Text }\end{array}$ & 2 & 0 \\
\hline
\end{tabular}

Fonte: Autores.

\subsection{LIMITES DA PESQUISA}

Foi utilizado um conjunto predeterminado de critérios de inclusão com o intuito de selecionar os documentos para esta revisão sistemática. Os documentos selecionados para inclusão na revisão sistemática foram analisados no que diz respeito aos seguintes critérios:

1. O estudo incluía um relatório de texto completo publicado em jornal, revista, revista académica ou revista especializada, analisado por especialistas;

2. O estudo incluía uma população de ambos os géneros e de todas as faixas etárias;

3. O estudo utilizava investigações do tipo transversal, longitudinal ou estudo caso;

4. O estudo incluía artigos escritos em inglês, português ou espanhol;

5. Não foram utilizados critérios de exclusão relativos à origem étnica.

Os artigos foram incluídos se preenchessem todos esses critérios precedentes. Estes artigos foram importados para um banco de dados de referência (Mendeley).

\subsection{AVALIAÇÃO DA QUALIDADE}

A avaliação da qualidade foi realizada com base em listas de avaliação padronizadas (CASTRO-PINERO et al., 2010; RUIZ-ARIZA et al., 2017), bem como nos critérios de seleção referidos acima. A lista incluiu cinco itens (A-E): A- Estudo com relatório de texto completo publicado em jornal, revista, revista académica ou revista especializada, analisado por especialistas; B- A população do estudo abrangia ambos os géneros e todas as faixas etárias; C- Os resultados da retenção de clientes dos centros de fitness eram claramente descritos; D- Os resultados incluíam informação relativa ao uso de tecnologias em centros de fitness; E- O tipo de investigação era transversal, longitudinal ou estudo caso.

Cada item foi classificado como '2' (se o critério era claro e totalmente referido no artigo analisado), ' 1 ' (se o critério era moderadamente referido no artigo analisado) ou '0' (se o critério não era referido ou estava pouco claro no artigo). Para todos os estudos foi calculado um índice de qualidade total, através da contagem do número de itens positivos numa pontuação total de 0 a 10 . Foram estabelecidos três níveis de 
evidência. Os estudos foram definidos como de alta qualidade (AQ), se a pontuação fosse igual ou superior a 8, de qualidade média (QM), se a pontuação total se situasse entre 5 e 7 e de qualidade baixa (QB), se a pontuação fosse igual ou inferior a 4. Assim, verificou-se que cinco artigos eram de alta qualidade e cinco de média qualidade (Quadro 2).

Quadro 2 - Lista de artigos com o respetivo nível de qualidade.

\begin{tabular}{|l|c|c|c|c|c|c|c|}
\hline \multicolumn{1}{|c|}{ Artigos } & A & B & C & D & E & $\begin{array}{c}\text { Pontuação } \\
\text { Total }\end{array}$ & $\begin{array}{c}\text { Nível de } \\
\text { Qualidade }\end{array}$ \\
\hline SPERANDEI; VIEIRA; REIS, 2016. & 2 & 2 & 1 & 0 & 2 & 7 & QM \\
\hline HERRERA et al., 2019. & 2 & 2 & 2 & 2 & 2 & 10 & $\mathrm{AQ}$ \\
\hline $\begin{array}{l}\text { MIDDELKAMP; ROOIJEN; } \\
\text { STEENBERGEN, 2016. }\end{array}$ & 2 & 2 & 1 & 0 & 2 & 7 & $\mathrm{QM}$ \\
\hline $\begin{array}{l}\text { GONÇALVES; MEIRELES; } \\
\text { CARVALHO, 2016. }\end{array}$ & 2 & 2 & 2 & 0 & 2 & 8 & $\mathrm{AQ}$ \\
\hline LEŚNIEWSKA, 2014. & 2 & 0 & 1 & 2 & 2 & 7 & $\mathrm{QM}$ \\
\hline $\begin{array}{l}\text { GOCŁOWSKA; PIACTKOWSKA; } \\
\text { LENARTOWICZ, 2013. }\end{array}$ & 2 & 2 & 1 & 0 & 2 & 7 & $\mathrm{QM}$ \\
\hline $\begin{array}{l}\text { GIUDICATI; RICCABONI; ROMITI, } \\
\text { 2013. }\end{array}$ & 2 & 2 & 2 & 0 & 2 & 8 & $\mathrm{AQ}$ \\
\hline $\begin{array}{l}\text { TSITSKARI; ANTONIADIS; } \\
\text { COSTA, 2014. }\end{array}$ & 2 & 2 & 2 & 0 & 2 & 8 & $\mathrm{AQ}$ \\
\hline LISTER et al., 2014. & 2 & 0 & 0 & 2 & 2 & 6 & $\mathrm{QM}$ \\
\hline $\begin{array}{l}\text { FERREIRA BARBOSA; } \\
\text { LOUREIRO; ALVES, 2019. }\end{array}$ & 2 & 2 & 2 & 0 & 2 & 8 & $\mathrm{AQ}$ \\
\hline
\end{tabular}

Fonte: Autores.

Nota: Avaliação para a pontuação total: Alta Qualidade $(A Q)=8-10$; Qualidade Média $(Q M)=5-7$; Qualidade Baixa $(Q B)=0-4$. A: Estudo com relatório de texto completo publicado em jornal, revista, revista académica ou revista especializada, analisado por especialistas. B: A população estudada abrange ambos os géneros e todas as faixas etárias. C: Os resultados da retenção de clientes dos centros de fitness foram claramente descritos. D: Os resultados incluíam informação relativa ao uso de tecnologias em centros de fitness. E: O tipo de investigação é transversal, longitudinal ou estudo caso.

\section{RESULTADOS}

O número total de artigos obtidos com a pesquisa foi de 458. Após a exclusão dos artigos duplicados, foram selecionados para leitura 362 artigos, dos quais se excluíram 322 pela leitura do título $(n=40), 25$ pela leitura do resumo $(n=15)$ e dois pela relevância do resultado. No total, foram considerados 13 artigos. Estes artigos foram analisados de acordo com os critérios de seleção, com base nos quais, foram excluídos três. Após essa seleção, foram incluídos na revisão sistemática dez artigos.

Uma análise detalhada desses estudos revelou que quatro eram transversais (40\%) (FERREIRA BARBOSA; LOUREIRO; ALVES, 2019; GOCŁOWSKA; PIĄTKOWSKA; LENARTOWICZ, 2019; GONÇALVES; MEIRELES; CARVALHO, 2016; TSITSKARI; ANTONIADIS; COSTA, 2014), quatro eram longitudinais (40\%) (GIUDICATI; RICCABONI; ROMITI, 2013; HERRERA et al., 2019; MIDDELKAMP; ROOIJEN; STEENBERGEN, 2016; SPERANDEI; VIEIRA; REIS, 2016) e dois eram estudos caso (20\%) (LEŚNIEWSKA, 2014; LISTER et al., 2014). 
Esta revisão inclui uma amostra com $n=16.370 .945$, cujo tamanho variou de 76 (GOCŁOWSKA; PIĄTKOWSKA; LENARTOWICZ, 2013) a 9674,945 participantes (GIUDICATI; RICCABONI; ROMITI, 2013). As amostras eram de 11 países diferentes: Portugal (FERREIRA BARBOSA; LOUREIRO; ALVES, 2019; GONÇALVES; MEIRELES; CARVALHO, 2016), Espanha (HERRERA et al., 2019; MIDDELKAMP; ROOIJEN; STEENBERGEN, 2016), Itália (GIUDICATI; RICCABONI; ROMITI, 2013; MIDDELKAMP; ROOIJEN; STEENBERGEN, 2016), França, Holanda, Bélgica, Luxemburgo, Alemanha (MIDDELKAMP; ROOIJEN; STEENBERGEN, 2016), Chipre (TSITSKARI; ANTONIADIS; COSTA, 2014), Brasil (SPERANDEI; VIEIRA; REIS, 2016) e Polónia (GOCŁOWSKA; PIĄTKOWSKA; LENARTOWICZ, 2019; LEŚNIEWSKA, 2014). Informações detalhadas sobre todos os estudos são apresentadas no Quadro 3, que se encontra no Apêndice, no final deste artigo.

O fluxograma dos resultados da pesquisa através do processo de revisão sistemática é apresentado na Figura 1

Figura 1 - Fluxograma dos documentos selecionados, segundo a recomendação PRISMA.

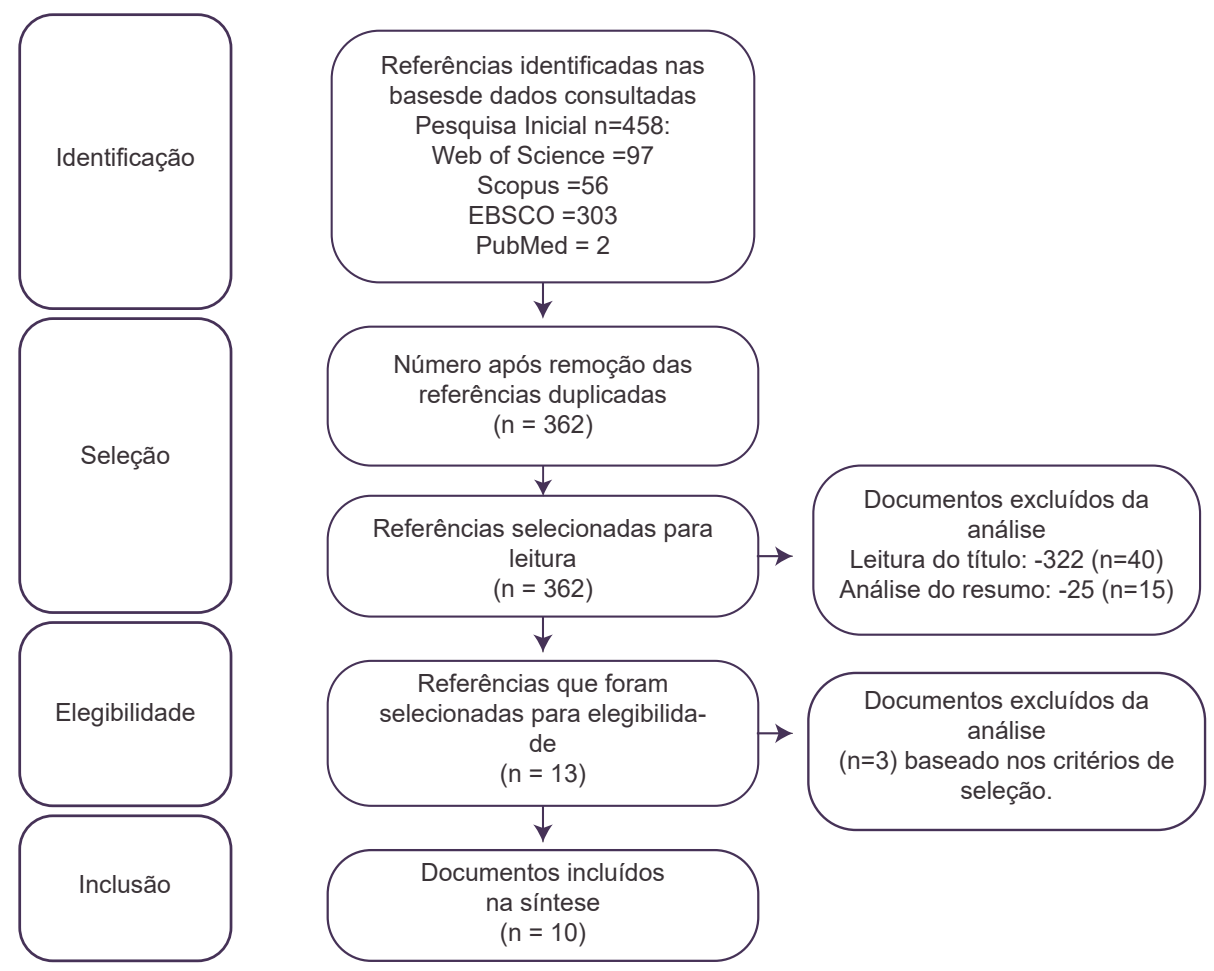

Fonte: Autores

\section{DISCUSSÃO}

As redes sociais revelam-se ferramentas indispensáveis para atrair novos clientes, aumentar a satisfação e as vendas e fortalecer a imagem da marca (HE; ZHA; LI, 2013). São vários os autores que relacionam a utilização das redes sociais com a retenção e fidelização do cliente no setor do fitness (BOWDEN, 2009; BRODIE et al., 2011; GARCÍA et al., 2015; PRAHALAD; RAMASWAMY, 2004). De acordo 
com García-Fernández et al. (2019), também a tecnologia está relacionada com a retenção. A utilização da tecnologia em ginásios, quando corretamente utilizada, representa um diferencial frente aos concorrentes do mercado, podendo proporcionar vantagem competitiva, diminuição dos custos e aumento dos lucros (BENTO et al., 2019).

Após a análise dos dez estudos, para além das variáveis redes sociais e tecnologias, foram também identificadas e analisadas as variáveis características pessoais dos sócios, frequência e tempo de utilização e qualidade do serviço e satisfação, como influenciadoras da retenção de sócios.

\subsection{VARIÁVEIS QUE INFLUENCIAM A RETENÇÃO DE CLIENTES}

\subsubsection{Redes Sociais}

Dos dez estudos analisados, dois investigam as redes sociais no contexto do fitness (GIUDICATI; RICCABONI; ROMITI, 2013; HERRERA et al., 2019). Para Giudicati et al. (2013), o impacto das redes sociais na satisfação e no compromisso do cliente deve ser levado em consideração, pois a inclusão de fatores sociais aumenta significativamente o poder preditivo do modelo de retenção de clientes. Em particular, o número e a intensidade dos vínculos sociais, isto é, a centralidade nas redes sociais, têm um papel significativo na restrição da taxa de rotatividade dos clientes. A gestão das redes sociais de experiência compartilhada desempenha um papel crucial na criação e manutenção de vantagem competitiva sustentável no setor de serviços.

De acordo com o estudo de Herrera et al. (2019), a análise das redes sociais no setor de fitness é uma realidade e uma necessidade para a fidelização e retenção de clientes, o que leva a procurar formas eficazes de as utilizar como parte da estratégia de marketing, para comunicar com os sócios e gerir o posicionamento da marca. Os resultados deste estudo indicam, ainda, o Facebook como a rede social mais utilizada, tendo-se verificado um aumento notável da utilização da rede social Instagram. Ainda assim, o Twitter verificou-se a $2^{2}$ rede mais utilizada, seguida do Instagram.

\subsubsection{Tecnologias}

Dos estudos selecionados, são quatro os que se referem ao uso da tecnologia no sector do fitness (GIUDICATI; RICCABONI; ROMITI, 2013; HERRERA et al., 2019; LEŚNIEWSKA, 2014; LISTER et al., 2014). No seu estudo, Leśniewska (2014) apresenta duas soluções tecnológicas de gestão da relação com o cliente (CRM) num clube de fitness, para garantir um bom e contínuo atendimento ao cliente, criando uma relação de longo prazo entre este e a empresa. Neste estudo, são apresentadas duas ferramentas de CRM de Informação Tecnológica (IT), o Perfect Gym-Club Management Software e o Suunto Fitness Solution, concebidas para gerir um health and fitness club ou um ginásio.

De acordo com a autora, as principais vantagens desse tipo de CRM são um contato constante e regular com o cliente (com um sistema de envio de relatórios), 
uma transferência sistemática de informações dentro da instituição (organizando o histórico de interações com clientes de alto risco), um controlo constante do progresso dos clientes e da sua atitude face ao treino, bem como um controlo da frequência de idas ao ginásio. Este revela-se um grande trunfo, da perspetiva interna da instituição. No entanto, o facto de serem constantemente solicitados aos sócios os dados pessoais (número de telefone, endereço de e-mail etc.), de serem abordados no ginásio e incentivados a conversar, o facto de serem incomodados por mensagens regulares enviadas automaticamente para o telemóvel ou e-mails com novas ofertas ou eventos pode ser percebido por alguns sócios como perturbador. As funções da ferramenta de IT apresentada ajudam a gerir o centro de fitness, sendo algumas opções voluntárias para o sócio (por exemplo, a utilização da aplicação móvel ou a sincronização com as redes sociais). Por outro lado, podem revelar-se uma desvantagem para os sócios, por exemplo, para aqueles que preferem alguma privacidade enquanto frequentam o ginásio. É um grande desafio definir a fronteira entre o que é esperado e aceite pelos sócios e o que não é.

Para os clientes interessados em observar regularmente o progresso do treino, os relatórios da Suunto enviados após as sessões podem ser altamente motivadores. A visualização na tela da frequência cardíaca e do consumo de energia durante as aulas de grupo, bem como o envio dos resultados por e-mail após a sessão, ajudam a aumentar a motivação dos clientes. Este relatório, em particular, é um exemplo de como o CRM funciona e de como a instituição se preocupa com os clientes, enviando-Ihes algumas orientações sobre o que fazer e a frequência com que devem treinar. A principal diferença entre o Perfect Gym e o Suunto Solution é que o primeiro é utilizado principalmente para apoiar o trabalho dos gestores com os clientes, enquanto o segundo é uma ferramenta usada para manter contato com os clientes e melhorar a sua motivação. No entanto, Leśniewska (2014) sugere o uso de ferramentas que possam apoiar a gestão em vários aspetos, tendo também em consideração a perspetiva dos clientes. Os dados organizados corretamente podem ser uma fonte rica de informações sobre as necessidades, hábitos, frequência de treino, tipo de atividade preferida, caráter de motivação, objetivos. Isto pode ser útil quando forem preparadas ofertas individuais para o cliente ou quando for necessário utilizar as estatísticas para gerir os horários das aulas em grupo ou fazer algumas classificações. Sabendo que cada cliente tem expectativas e necessidades diferentes, é crucial garantir que os dados sejam analisados adequadamente e que seja apresentada uma oferta única e individualizada ao cliente, para garantir um serviço profissional. Esses aspetos fazem diferença quando se trata de escolher o serviço e podem criar uma relação de longo prazo entre o cliente e a empresa (LEŚNIEWSKA, 2014). Portanto, à vista deste artigo, pode-se deduzir que estes CRM facilitam a retenção de clientes em centros de fitness.

Outros estudos, como o de Giudicati et al. (2013), investigam a tecnologia RFID (Radio Frequency Identification). Os autores trazem algumas ideias sobre como os gestores podem aproveitar as informações geradas por RFID para melhorar a satisfação e o compromisso do cliente. A conclusão a que chegam sugere que essa tecnologia deve ser profundamente integrada nos sistemas de gestão de relação com o cliente, pois é um modo de reunir e partilhar informações do cliente. Estes 
sistemas inteligentes de rastreio de cliente para cliente devem ser combinados com o marketing boca a boca, para aumentar a lealdade do cliente (GIUDICATI; RICCABONI; ROMITI, 2013).

Ainda no tema das tecnologias, no que diz respeito às páginas web dos ginásios, ficou provado que a sua popularidade diminuiu (HERRERA et al., 2019). Verifica-se, portanto, uma utilização cada vez menos recorrente deste tipo de tecnologia.

Por último, Lister et al. (2014) analisaram a gamificação das aplicações de saúde e fitness, como um potencial influenciador no comportamento de saúde de um consumidor. Os autores verificaram, pelo número de aplicações encontradas na Apple App Store que contêm alguns componentes da gamificação, que o seu uso em aplicações de saúde e fitness se tornou bastante popular. As aplicações representam um mercado muito promissor para criar um comportamento de mudança na área da saúde. De modo geral, os resultados revelaram um uso abundante da gamificação em aplicações de saúde e fitness (LISTER et al., 2014). Ainda que não seja diretamente mencionado no artigo, pensa-se que a gamificação influencia positivamente a retenção de clientes.

\subsubsection{Características Pessoais}

Da totalidade dos dez estudos, são três os que se referem às características pessoais do cliente no processo de renovação e retenção (FERREIRA BARBOSA; LOUREIRO; ALVES, 2019; GIUDICATI; RICCABONI; ROMITI, 2013; SPERANDEI; VIEIRA; REIS, 2016). Giudicati et al. (2013) verificaram que as características individuais desempenham um papel importante nas decisões de renovação. As características pessoais, como género dos clientes e a idade, afetam significativamente as decisões de abandono dos centros de fitness pelos clientes. Os autores concluíram que trabalhadores, imigrantes, homens e jovens clientes revelaram menor hipótese de renovar a inscrição.

De acordo com Sperandei, Vieira e Reis (2016), as variáveis idade, nível de atividade física e índice de massa corporal e as motivações para perda peso, saúde, estética e hipertrofia estão relacionadas com a probabilidade de um indivíduo se manter retido no ginásio. Através do seu estudo, criaram estimativas para o perfil do melhor prognóstico: acima de 35 anos, ativo, não motivado pela perda de peso e motivado pela hipertrofia, saúde e estética; e do pior prognóstico: idade até 25 anos, que nunca praticou atividade física, motivado pela perda de peso e não motivado pela hipertrofia, saúde ou estética. Mesmo os indivíduos que apresentam a melhor combinação de variáveis ainda apresentam alto risco de abandono antes dos 12 meses de associação ao ginásio (SPERANDEI; VIEIRA; REIS, 2016). Pelo contrário, no seu estudo, Ferreira Barbosa, Loureiro e Alves (2019) verificaram que as características pessoais dos sócios, nomeadamente o género, idade e as habilitações académicas, não influenciam a satisfação global dos sócios e, por sua vez, a retenção.

\subsubsection{Frequência e Tempo de Utilização}

São cinco os estudos que procuram examinar a frequência e/ou tempo de utilização no contexto da retenção (FERREIRABARBOSA; LOUREIRO; ALVES, 2019; 
GIUDICATI; RICCABONI; ROMITI, 2013; GONÇALVES; MEIRELES; CARVALHO, 2016; MIDDELKAMP; ROOIJEN; STEENBERGEN, 2016; SPERANDEI; VIEIRA; REIS, 2016). De acordo com o estudo de Gonçalves et al. (2016), a frequência semanal (número de assistências ao ginásio) não mostra capacidade explicativa para predizer a satisfação e retenção, ou seja, a frequência semanal não contribui para maior satisfação ou retenção. Ferreira Barbosa et al. (2019) verificaram também que o tempo de utilização, frequência e horário de utilização do ginásio não influenciam a satisfação global dos sócios e, assim, a retenção.

No seu estudo, Middelkamp, Rooijen e Steenbergen (2016) aplicaram as fases de mudança do Modelo Transteórico de Mudança de Comportamento para analisar os padrões de comportamento dos participantes em centros de fitness. Os resultados revelaram que apenas $10 \%$ dos sócios alcançaram a fase de manutenção (Atividade Física regular há mais de seis meses) sem recaídas, mas que estes têm maior probabilidade de continuar a frequentar até ao $12^{\circ}$ mês, mesmo com frequências baixas. Os resultados deste estudo indicaram que 19,5\% nunca frequentaram o ginásio. O comportamento médio de frequência foi extremamente baixo e a sua diminuição foi substancial - 12,5 vezes menor no $24^{\circ}$ mês, em comparação ao primeiro mês completo. Os resultados revelaram que apenas 2,3\% nunca tiveram uma recaída durante os 24 meses e que $50 \%$ dos que tiveram uma recaída durante um mês reiniciaram no mês seguinte.

Com o seu estudo, Sperandei, Vieira e Reis (2016) concluíram que $63 \%$ dos novos sócios abandonarão as atividades antes do terceiro mês e menos de $4 \%$ permanecerão por mais de 12 meses de atividade contínua. De acordo com estes estudos torna-se claro que devem ser desenvolvidas estratégias apropriadas para melhorar o comportamento de frequência e, assim, a retenção de clientes.

O estudo de Giudicati, Riccaboni e Romiti (2013) contribuiu para uma melhor compreensão do papel da experiência no compromisso do cliente e nas decisões de renovação, distinguindo três componentes da experiência do cliente: posse (tempo em meses de permanência no ginásio), padrões de uso (representado pelo preço por presença-rácio entre o preço do contrato e o número de presenças durante sua vigência) e relação com o cliente. A posse e os padrões de uso demonstraram ter um efeito negativo na probabilidade de renovação do contrato, verificou-se, portanto, que ambas afetam as decisões de renovação. Verificaram que quanto mais longa a associação ao health club, menor a probabilidade de renovação e também que os clientes que pagam um preço mais alto por presença (menor uso do contrato) têm maior probabilidade de renovar inscrição. O tempo decorrido da expiração do contrato tem um efeito negativo, confirmando que a maioria das decisões de renovação é tomada imediatamente após a expiração do contrato anterior.

\subsubsection{Qualidade do Serviço e Satisfação de Clientes}

Dos dez estudos analisados, quatro verificam a relação das variáveis satisfação dos sócios e qualidade do serviço com a retenção de clientes (FERREIRA BARBOSA; LOUREIRO; ALVES, 2019; GOCŁOWSKA; PIĄTKOWSKA; LENARTOWICZ, 2019; GONÇALVES; MEIRELES; CARVALHO, 2016; TSITSKARI; ANTONIADIS; COSTA, 
2014). Gocłowska, Piątkowska e Lenartowicz (2019) indicam que para melhorar a qualidade dos serviços oferecidos é fundamental medir a satisfação do cliente. De acordo com os autores, as empresas devem focar-se mais nas áreas que identificaram como pontos fracos e ameaças em termos de nível de satisfação do sócio do fitness club: a localização, o preço e as atividades promocionais do fitness club.

Tsitskari, Antoniadis e Costa (2014) concluíram com o seu estudo que a qualidade do serviço, mais especificamente, a dimensão funcionários, prevê direta e indiretamente, através da satisfação do cliente, o compromisso psicológico. Os autores destacam, então, a importância das estratégias de recrutamento e de treino do staff para a retenção de clientes. Tsitskari, Antoniadis e Costa (2014) defendem ainda que a criação de uma atmosfera calorosa e amigável nas instalações e nas aulas deve ser uma prioridade e que tanto a equipa administrativa quanto os profissionais de fitness devem contribuir nesse sentido. Para os mesmos autores, perceções positivas da qualidade do serviço levam a uma satisfação maior, o que, por sua vez, leva ao compromisso do cliente e, possivelmente, à retenção do cliente.

No seu estudo, Ferreira Barbosa, Loureiro e Alves (2019) verificaram também que existe uma relação positiva entre perceção da qualidade do serviço e satisfação global dos clientes, influenciando a retenção. Neste estudo, a qualidade dos serviços apresenta uma maior relevância para a satisfação global dos sócios, seguido da qualidade dos equipamentos e, por fim, a relação qualidade/preço.

De acordo com Gonçalves, Meireles e Carvalho (2016), a satisfação depende muito das expectativas dos sócios sobre o serviço. Portanto, é importante manter constantemente e, se possível, exceder as expectativas dos sócios para que eles permaneçam satisfeitos por mais tempo. Assim, quando os gerentes intervêm nas expectativas em relação à satisfação do cliente com o serviço, eles influenciam a retenção (GONÇALVES; MEIRELES; CARVALHO, 2016).

\section{CONCLUSÃO}

A constante expansão dos centros de fitness leva a que os gestores procurem formas de reter e atrair novos clientes. Deste ponto de vista, com esta revisão sistemática, procurou-se identificar a influência das redes sociais e tecnologias na retenção de clientes em centros de fitness.

A pesquisa foi efetuada em quatro bases de dados, de 2011 a 2019. Um total de dez artigos correspondeu aos critérios de inclusão dos quais quatro eram transversais, quatro longitudinais e dois estudos de caso. Dentre os dez estudos, para além das variáveis redes sociais e tecnologias, verificou-se que as variáveis características pessoais dos sócios, frequência e tempo de utilização, qualidade do serviço e satisfação também apresentavam influência na retenção de clientes. Podemos agrupar essas variáveis em duas dimensões, uma associada com o ginásio (tecnologias e redes sociais) e outra mais ligada ao cliente (características pessoais, satisfação, perceção de qualidade do serviço, frequência semanal de utilização), conforme mostra a Figura 2. 
Dois estudos identificaram a importância das redes sociais no processo de retenção de clientes (GIUDICATI; RICCABONI; ROMITI, 2013; HERRERA et al., 2019). No que toca às tecnologias, um estudo destacou duas ferramentas de CRM como uma oferta importante para criar uma relação duradoura cliente-empresa (LEŚNIEWSKA, 2014). Outro estudo apontou a tecnologia Radio Frequency Identification (RFID) para o aumento da fidelidade do cliente (GIUDICATI; RICCABONI; ROMITI, 2013). Quanto às páginas web dos ginásios, um estudo indicou que a sua popularidade tem vindo a diminuir (HERRERA et al., 2019). Apenas um estudo se referiu à gamificação das aplicações de saúde e fitness como influenciador no comportamento de saúde (LISTER et al., 2014) e, ainda que não seja diretamente referenciado no estudo, pensa-se que a gamificação influencia positivamente a retenção de clientes. Concluise, portanto, que as redes sociais e o uso das tecnologias têm uma influencia positiva na retenção de clientes em ginásios. Na Figura 2 as variáveis relacionadas a empresa e ao cliente:

Figura 2 - Framework com as conclusões.

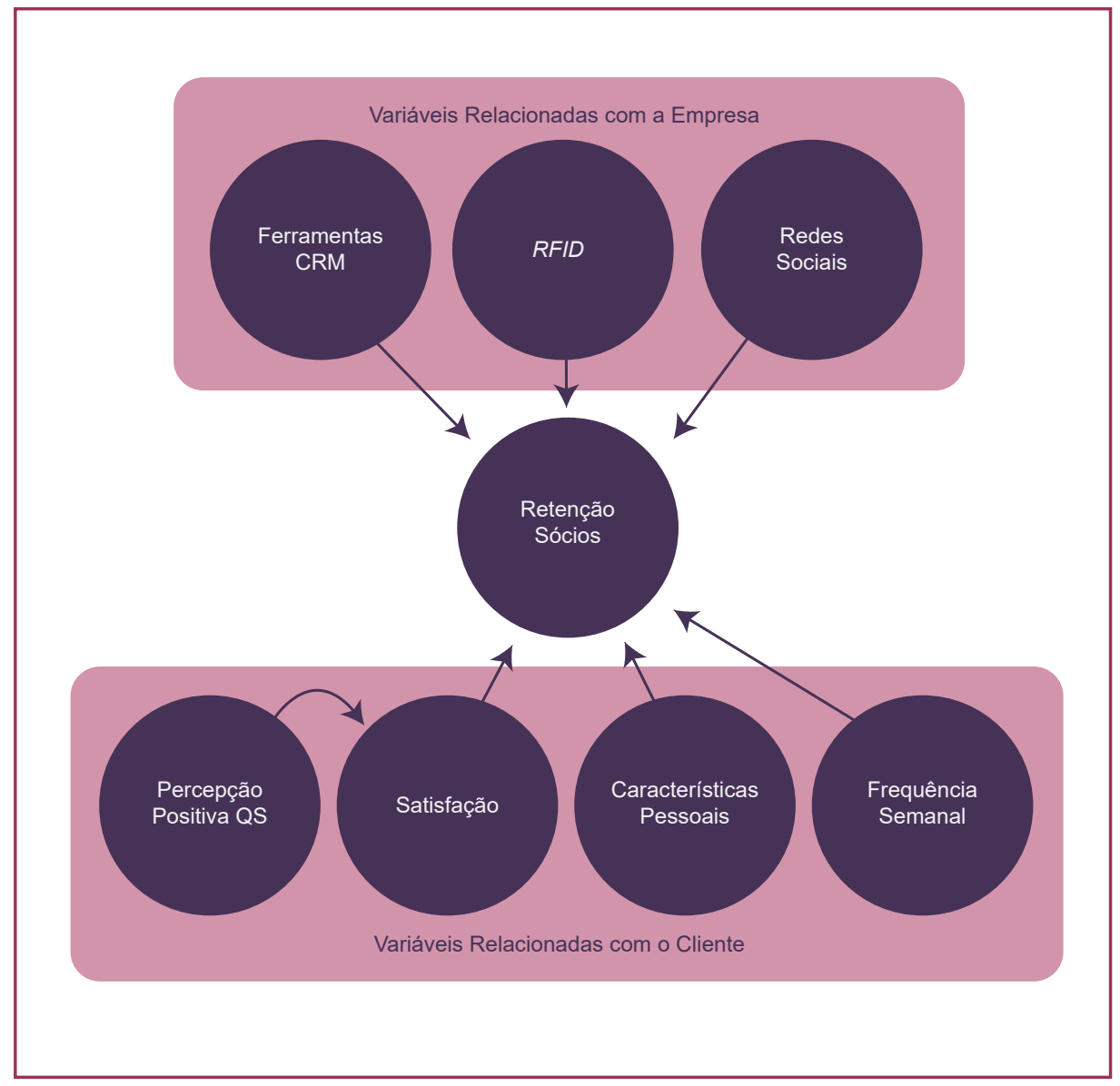

Fonte: os autores

Há três estudos que se referem às características pessoais dos sócios (FERREIRA BARBOSA; LOUREIRO; ALVES, 2019; GIUDICATI; RICCABONI; ROMITI, 2013; SPERANDEI; VIEIRA; REIS, 2016). Desses, dois referem a sua influência no processo de renovação (GIUDICATI; RICCABONI; ROMITI, 2013; SPERANDEI; VIEIRA; REIS, 2016). 
São dois os estudos que afirmam que a frequência semanal não mostra capacidade explicativa para predizer a satisfação e retenção (FERREIRA BARBOSA; LOUREIRO; ALVES, 2019; GONÇALVES; MEIRELES; CARVALHO, 2016). No entanto, dois estudos indicam que devem ser desenvolvidas estratégias para melhorar o comportamento de frequência (MIDDELKAMP; ROOIJEN; STEENBERGEN, 2016; SPERANDEI; VIEIRA; REIS, 2016), o que sugere a sua influencia na retenção de clientes.

Medir a satisfação revela-se fundamental paramelhorar a qualidade dos serviços (GOCŁOWSKA; PIĄTKOWSKA; LENARTOWICZ, 2019). São três os estudos que sugerem que perceções positivas da qualidade do serviço levam a maior satisfação dos sócios e, por sua vez, à retenção (FERREIRA BARBOSA; LOUREIRO; ALVES, 2019; GONÇALVES; MEIRELES; CARVALHO, 2016; TSITSKARI; ANTONIADIS; COSTA, 2014). A qualidade dos serviços deve ser tida em conta já que padrões de alta qualidade levam a clientes mais satisfeitos e por sua vez mais fiéis.

É importante perceber que a criação do valor da empresa deve ser guiada pelo valor percebido pelos clientes (MARTELO-LANDROGUEZ; BARROSO; CEPEDACARRIÓN, 2013). Por isso, é importante distinguir o que a empresa perceciona como qualidade, mas principalmente a perceção de qualidade do cliente sobre os serviços que oferece a empresa. Isto porque a satisfação (e consequentemente a retenção) depende muito das expectativas dos sócios sobre o serviço. Portanto, sugere-se, como futura linha de investigação, integrar as diferentes perspetivas de qualidade (empresa e cliente) relacionadas ao uso das tecnologias e como esse uso influenciaria a retenção de clientes.

\section{LIMITAÇÕES}

Existem algumas limitações nesta revisão que devem ser mencionadas. Em primeiro lugar, o facto de não existirem muitos estudos incluídos na revisão final, apesar dos termos de busca terem sido cuidadosamente escolhidos de acordo com o tema principal do estudo. Em segundo lugar, o estudo está relacionado apenas com a opinião de três revisores. Como terceira limitação apontamos o facto de não se terem considerado as diferenças sociodemográficas da população dos diferentes estudos.

\section{REFERÊNCIAS}

AKERMAN, Anders; GAARDER, Ingvil; MOGSTAD, Magne. The skill complementarity of broadband internet. The Quarterly Journal of Economics, v. 130, n. 4, p. 1781-1824, 2015.

ALONSO-DOS-SANTOS, M.; SOTO-FUENTES, Y.; VALDERRAMA-PALMA, V. A. Determinants of Mobile Banking Users' Loyalty. Journal of Promotion Management, v. 26, n. 5, p. 615-633, 2020. 
BODET, Guillaume. Loyalty in sports participation services: an examination of the mediating role of psychological commitment. Journal of Sport Management, v. 26, n. 1, p. 30-42, 2012.

BOWDEN, Jana Lay-Hwa. The process of customer engagement: a conceptual framework. Journal of Marketing Theory and Practice, v. 17, n. 1, p. 63-74, 2009.

BREM, Alexander; VOIGT, Kay-Ingo. Integration of market-pull and technology-push in the corporate front end and innovation management - Insights from the German software industry. Technovation, v. 29, p. 351-367, 2009.

BRODIE, Roderick et al. Customer engagement: Conceptual domain, fundamental propositions, and implications for research. Journal of Service Research, v. 14, p. 252271, 2011.

CASTRO-PINERO, José et al. Criterion-related validity of field-based fitness tests in youth: a systematic review. British journal of sports medicine, v. 44, n. 13, p. 934-943, 2010.

DU, Honglu et al. A Group- Based Mobile Application to Increase Adherence in Exercise and Nutrition Programs: A Factorial Design Feasibility Study. JMIR mHealth and uHealth, v. 4, n. 1, e4, 2016. Disponível em: https://pubmed.ncbi.nlm.nih.gov/26772910/ DOI: https://doi. org/10.2196/mhealth.4900

FERRAND, Alain; ROBINSON, Leigh; VALETTE-FLORENCE, Pierre. The Intentionto-Repurchase Paradox: A Case of the Health and Fitness Industry. Journal of Sport Management, v. 84, p. 83-105, 2010.

FERREIRA BARBOSA, Helena; LOUREIRO, Vânia; ALVES, Ana. Quality and satisfaction in gymnasiums \& health clubs. Materiales para la Historia del Deporte, v. 18, p. 115-121, 2019.

GAMBOA, Ana Margarida; GONÇALVES, Helena Martins. Customer loyalty through social networks: Lessons from Zara on Facebook. Business Horizons, v. 57, n. 6, p. 709-717, 2014.

GARCÍA, Jerónimo et al. Influencia de la utilización de facebook y web en la fidelidad de clientes de centros de fitness. Revista Intercontinental de Gestão Desportiva, v. 5, n. 2, p. 203-205, 2015.

GARCÍA-FERNÁNDEZ, Jerónimo et al. An analysis of new social fitness activities: loyalty in female and male CrossFit users. Sport in Society, v. 23, n. 2, p. 204-221, 2019.

GARCÍA-FERNÁNDEZ, Jerónimo et al. Social networks in fitness centres: the impact of fan engagement on annual turnover. Journal of Physical Education and Sport, v. 17, n. 3, p. 1068-1077, 2017.

GIUDICATI, Gianna; RICCABONI, Massimo; ROMITI, Anna. Experience, socialization and customer retention: Lessons from the dance floor. Marketing Letters, v. 24, n. 4, p. 409422, 2013.

GOCŁOWSKA, Sylwia; PIĄTKOWSKA, Monika; LENARTOWICZ, Michal. Customer satisfaction and its measurement in fitness clubs of Warsaw. Economics and Sociology, v. 12, p. 205-2018, 2019.

GONÇALVES, Celina; MEIRELES, Pedro; CARVALHO, Maria José. Consumer Behaviour in Fitness Club: Study of the Weekly Frequency of use, Expectations, satisfaction and Retention. The Open Sports Sciences Journal, v. 9, p. 1-9, 2016. 
HALLOWELL, Roger. The relationships of customer satisfaction, customer loyalty, and profitability: An empirical study. International Journal of Service Industry Management, v. 7, n. 4, p. 27-42, 1996.

HASSAN, Mohamad; HUSSAIN, Fawad; RAHMAN, Mihraj Begum Binti Saib. Exploring usefulness of CRM and it in Malaysian hotel industry: A qualitative approach. Journal of Information and Communication Technology, v. 12, n. 1, p. 21-37, 2013.

HE, Wu; ZHA, Shenghua; LI, Ling. Social media competitive analysis and text mining: A case study in the pizza industry. International Journal of Information Management, v. 33, n. 3, p. 464-472, 2013.

HERRERA, Lucía. et al. Análisis de las redes sociales en el sector del fitness español: un estudio longitudinal. Materiales para la Historia del Deporte, v. 18, p. 122-128, 2019.

KARIMI, Jahangir; SOMERS, Toni; GUPTA, Yash. Impact of Information Technology Management Practices on Customer Service. Journal of Management Information Systems, v. 17, p. 125-158, 2001.

KIMES, Sheryl E. Customer perceptions of electronic food ordering. Cornell Hospitality Report, v. 11, n. 10, p. 6-15, 2011.

LEŚNIEWSKA, Aleksandra. Customer relationship management in a fitness club - case study of IT solutions applied in a selected organization. Business Informatics, v. 34, p. 66-76, 2014.

LISTER, Cameron et al. Just a Fad? Gamification in Health and Fitness Apps. JMIR serious games, v. 2, p. e9, 2014. DOI: https://doi.org/0.2196/games.3413

MADHOVI, Previledge Garikay; DHLIWAYO, Shepherd. The relationship between customer relationship management (CRM) and performance in the hotel industry. African Journal of Hospitality, Tourism and Leisure, v. 6, n. 1, p. 1-13, 2017.

MARTELO-LANDROGUEZ, Silvia; BARROSO, Carmen; CEPEDA-CARRIÓN, Gabriel. Developing an integrated vision of customer value. Journal of Services Marketing, v. 27, n. 3, p. 234-244, 2013.

MATIŞ, Ciprian; LIVIU, Ilies. Customer Relationship Management in the Insurance Industry. Procedia Economics and Finance, v. 15, n. 2014, p. 1138-1145, 2014.

MIDDELKAMP, Jan; ROOIJEN, Maaike Van; STEENBERGEN, Bert. Attendance Behavior of Ex-members in Fitness Clubs: A Retrospective Study Applying the Stages of Change.

Perceptual and Motor Skills, v. 122, n. 1, p. 350-359, 2016.

MOHER, David et al. The PRISMA Group. Preferred reporting items for systematic reviews and meta-analyses: The PRISMA Statement. PLoSMed, v. 6, n. 7, jul. 2009. Disponível em: https:// doi.org/10.1371/journal.pmed.1000097. Acesso em: 3 dez. 2019.

NG, Soo-Ryue; WONG, Shiun-Yi; CHONG, Lily. Outsourcing to Online Food Delivery Services: Perspective of F\&B Business Owners. Journal of Internet Banking and Commerce, v. 22, n. 2, p. 1-13, 2017.

OLIVER, Richard. Whence consumer loyalty. Journal of Marketing, v. 63, p. 33-44, 1999.

PEDRAGOSA, Vera. Satisfação e Fidelização em Ginásios e Health Clubs: Estudo das Expetativas, das Emoções e da Qualidade. 2012. 197f. Dissertação (Doutor em Motricidade Humana na Especialidade de Ciências do Desporto) - Faculdade de Motricidade Humana, Universidade Técnica de Lisboa, 2012. 
PRAHALAD, C. K.; RAMASWAMY, Venkat. Co-creation experiences: The next practice in value creation. Journal of Interactive Marketing, v. 18, n. 3, p. 5-14, 2004.

RICHTER, Jason P.; KAZLEY, Abby S. Social media: How hospital facebook activity may influence patient satisfaction. Health Marketing Quarterly, v. 37, n. 1, p. 1-9, 2020.

RUIZ-ARIZA, Alberto. et al. Influence of physical fitness on cognitive and academic performance in adolescents: A systematic review from 2005-2015. International Review of Sport and Exercise Psychology, v. 10, n. 1, p. 108-133, 2017.

SANTOSO, Radityo Kusumo; DEWI, Nur Fadillah. Social Media Marketing's Influence on Customer Loyalty: A Case Study of Siloam Hospital. In: INTERNATIONAL CONFERENCE ON VOCATIONAL HIGHER EDUCATION (ICVHE 2018), Anais: Atlantis Press, v. 426, p. 224-232, 2020.

SHAIKH, Aijaz A.; KARJALUOTO, Heikki. Mobile banking adoption: A literature review. Telematics and Informatics, v. 32, n. 1, p. 129-142, 2015.

SOUSA, Maria José; ROCHA, Álvaro. Skills for disruptive digital business. Journal of Business Research, v. 94, p. 257-263, 2019.

SPERANDEI, Sandro; VIEIRA, Marcelo C.; REIS, Arianne C. Adherence to physical activity in an unsupervised setting: Explanatory variables for high attrition rates among fitness center members. Journal of Science and Medicine in Sport, v. 19, n. 11, p. 916-920, 2016.

TALLEY, M. Customer retention: A manager's perspective. In: OAKLEY, Ben; RHYS, Martin (eds.) The Sport and Fitness Sector: An Introduction. London: Routledge, 2008.

TSITSKARI, Efi; ANTONIADIS, CH; COSTA, Giulia. Investigating the relationship among service quality, customer satisfaction \& psychological commitment in Cyprian fitness centres. Journal of Physical Education \& Sport, v. 14, p. 514-520, 2014.

TU, Rungting; HSIEH, Peishan; FENG, Wenting. Walking for fun or for "likes"? The impacts of different gamification orientations of fitness apps on consumers' physical activities. Sport Management Review, v. 22, n. 5, p. $682-693,2018$.

VALCARCE, Manuel; DÍEZ-VALGO, Carlota. Influencia de una app en la adherencia a la práctica deportiva: protocolo de estudio. e-Motion: Revista de Educación, Motricidad e Investigación, v. 11, p. 16-34, 2018.

VASCONCELOS, José Braga; KIMBLE, Chris; ROCHA, Álvaro. A special issue on knowledge and competence management: Developing Enterprise solutions. Information Systems Frontiers, v. 18, n. 6, p. 1035-1039, 2016.

VOTH, Elizabeth C.; OELKE, Nelly D.; JUNG, Mary E. A Theory-Based Exercise App to Enhance Exercise Adherence: A Pilot Study. JMIR mHealth and uHealth, v. 4, n. 2, e62, 2016. Disponível em: https://pubmed.ncbi.nlm.nih.gov/27307134/ DOI: https://doi. org/10.2196/mhealth.4997

YEO, Vincent Cheow Sern; GOH, See-Kwong; REZAEI, Sajad. Consumer experiences, attitude and behavioral intention toward online food delivery (OFD) services. Journal of Retailing and Consumer Services, v. 35, p. 150-162, 2017.

ZANATTA, Thaís et al. O perfil do gestor esportivo brasileiro: revisão sistemática da literatura. Movimento, v. 24, n. 1, p. 291-304, 2018. 


\section{APÊNDICE}

Quadro 3 - Características dos estudos analisados $(n=10)$.

\begin{tabular}{|c|c|c|c|}
\hline Autores/ Ano/ Título & Objetivo & Amostra/ País & Resultados \\
\hline $\begin{array}{l}\text { Sperandeia, S.; Vieira, Marcelo C.; } \\
\text { Reis, Arianne. } 2016 .\end{array}$ & \multirow[b]{2}{*}{$\begin{array}{l}\text { Avaliar a taxa de } \\
\text { desistência dos sócios } \\
\text { de um centro de } \\
\text { fitness na cidade do } \\
\text { Rio de Janeiro e as } \\
\text { possíveis variáveis } \\
\text { explicativas para o } \\
\text { fenómeno. }\end{array}$} & \multirow[b]{2}{*}{$\begin{array}{l}5240 \text { sócios. } \\
\text { Brasil. }\end{array}$} & \multirow[b]{2}{*}{$\begin{array}{l}\text { 1. } 63 \% \text { dos novos sócios abandonarão as atividades antes do terceiro mês } \\
\text { e menos de } 4 \% \text { permanecerão por mais de } 12 \text { meses de atividade contínua. } \\
\text { 2. Variáveis relacionadas significativamente à probabilidade de um indivíduo } \\
\text { permanecer como membro ativo do centro de fitness: idade, nível de atividade } \\
\text { física e índice de massa corporal e as motivações 'perda de peso', 'saúde', } \\
\text { 'estética' e 'hipertrofia'. } 3 \text {. A partir da combinação das variáveis consideradas } \\
\text { significativas no modelo, é possível criar perfis de indivíduos representativos e } \\
\text { uma estimativa da probabilidade de longevidade para cada mês. } 4 \text {. Mesmo os } \\
\text { indivíduos que apresentam a melhor combinação de variáveis ainda apresentam } \\
\text { alto risco de abandono antes dos } 12 \text { meses de associação ao centro de fitness. }\end{array}$} \\
\hline $\begin{array}{l}\text { Adherence to physical activity in an } \\
\text { unsupervised setting: Explanatory } \\
\text { variables for high attrition rates } \\
\text { among fitness center members. }\end{array}$ & & & \\
\hline $\begin{array}{l}\text { Herrera-Torres, L.; Pérez-Tur, F.; } \\
\text { Valcarce Torrente, M. y García- } \\
\text { Fernández, J. } 2019 .\end{array}$ & \multirow{2}{*}{$\begin{array}{l}\text { Analisar a evolução } \\
\text { das redes sociais no } \\
\text { setor de fitness em } \\
\text { Espanha durante o } \\
\text { período de } 2015 \text { a } \\
2018 \text {. }\end{array}$} & \multirow{2}{*}{$\begin{array}{l}215 \text { empresas. } \\
\text { Espanha }\end{array}$} & \multirow{2}{*}{$\begin{array}{l}\text { 1. As organizações desportivas estão a perceber os benefícios das redes sociais } \\
\text { e a procurar formas eficazes de as utilizar como parte de seu marketing global, } \\
\text { para comunicar com os sócios e gerir as estratégias da marca. } 2 \text {. A análise de } \\
\text { redes sociais no setor de fitness é uma realidade e uma necessidade. } 3 \text {. Desceu } \\
\text { a popularidade das páginas web. } 4 \text {. Os resultados indicaram o Facebook como a } \\
\text { rede social mais utilizada e um aumento notável da rede social do Instagram. } 5 \text {. } \\
\text { Ainda assim, o Twitter é a } 2^{a} \text { rede mais utilizada seguida do Instagram. }\end{array}$} \\
\hline $\begin{array}{l}\text { Analysis Of Social Networks In } \\
\text { The Spanish Fitness Sector: A } \\
\text { Longitudinal Study. }\end{array}$ & & & \\
\hline $\begin{array}{l}\text { Middelkamp, J; Van Rooijen, M.; } \\
\text { Steenbergen, B. } 2016 .\end{array}$ & \multirow{2}{*}{$\begin{array}{l}\text { Aplicar as fases } \\
\text { de mudança do } \\
\text { Modelo Transteórico } \\
\text { de mudança de } \\
\text { comportamento para } \\
\text { analisar os padrões } \\
\text { de comportamento } \\
\text { dos participantes em } \\
\text { centros de fitness. }\end{array}$} & \multirow{2}{*}{$\begin{array}{l}400 \text { sócios. } \\
\text { Holanda, } \\
\text { Bélgica, } \\
\text { Luxemburgo, } \\
\text { Alemanha, } \\
\text { França, } \\
\text { Espanha e } \\
\text { Itália }\end{array}$} & \multirow{2}{*}{$\begin{array}{l}\text { 1. O comportamento de frequência dos } 400 \text { ex-sócios revelou-se problemático } \\
\text { em relação à manutenção da saúde. } 2 \text {. Apenas } 10 \% \text { dos sócios alcançaram a } \\
\text { fase de manutenção sem recaídas. } 3.19,5 \% \text { nunca frequentaram o centro. } 4 \text {. O } \\
\text { comportamento médio de frequência foi extremamente baixo e a sua diminuição } \\
\text { foi substancial - } 12,5 \text { vezes menor no } 24^{\circ} \text { mês em comparação ao primeiro mês } \\
\text { completo. } 5 \text {. Apenas } 2,3 \% \text { dos ex-sócios nunca tiveram uma recaída durante } \\
\text { os } 24 \text { meses. } 6.50 \% \text { dos ex-sócios que tiveram uma recaída durante um mês } \\
\text { reiniciou no mês seguinte. } 7 \text {. Ex-sócios que atingem a fase da manutenção } \\
\text { têm maior probabilidade de continuar a frequentar até ao } 12^{\circ} \text { mês, mesmo com } \\
\text { frequências baixas. }\end{array}$} \\
\hline $\begin{array}{l}\text { Attendance Behavior of Ex- } \\
\text { members in Fitness Clubs: A } \\
\text { Retrospective Study Applying the } \\
\text { Stages of Change. }\end{array}$ & & & \\
\hline
\end{tabular}

Continua na próxima página...

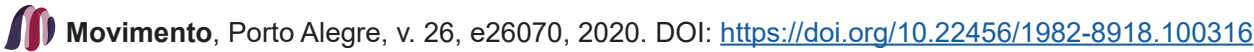


Continuação do quadro 3

\begin{tabular}{|c|c|c|c|}
\hline $\begin{array}{l}\text { Gonçalves, C.; Meireles, P.; } \\
\text { Carvalho, M. J. } 2015 .\end{array}$ & \multirow{2}{*}{$\begin{array}{l}\text { Compreender } \\
\text { a relação entre } \\
\text { frequência semanal de } \\
\text { treino, as expectativas, } \\
\text { a satisfação e a } \\
\text { retenção de sócios em } \\
\text { centros de fitness. }\end{array}$} & \multirow[b]{2}{*}{$\begin{array}{l}146 \text { sócios. } \\
\text { Portugal. }\end{array}$} & \multirow{2}{*}{$\begin{array}{l}\text { 1. A frequência semanal não mostrou capacidade explicativa para predizer a } \\
\text { satisfação e retenção (a frequência semanal não contribui para maior satisfação } \\
\text { ou retenção.). } 2 \text {. A relação entre as expectativas, a satisfação }(73 \%) \text { e a retenção } \\
(64 \%) \text { foi estatisticamente significante. } 3 \text {. A relação entre satisfação e retenção } \\
(63 \%) \text { foi positiva e significativa. }\end{array}$} \\
\hline $\begin{array}{l}\text { Consumer behaviour in fitness club: } \\
\text { Study of the weekly frequency of } \\
\text { use, expectations, satisfaction and } \\
\text { retention. }\end{array}$ & & & \\
\hline Leśniewska, A. 2014. & \multirow{2}{*}{$\begin{array}{l}\text { Apresentar uma forma } \\
\text { de aplicar o conceito } \\
\text { de CRM (Customer } \\
\text { Relationship } \\
\text { Management) numa } \\
\text { instituição desportiva } \\
\text { e discutir as suas } \\
\text { funções e a sua } \\
\text { utilidade, através de } \\
\text { duas ferramentas } \\
\text { (Perfect Gym-Club } \\
\text { Management Software } \\
\text { e Suunto Fitness } \\
\text { Solution). }\end{array}$} & \multirow[t]{2}{*}{ Polónia. } & \multirow{2}{*}{$\begin{array}{l}\text { 1. As soluções de IT apresentadas têm vários recursos de suporte à abordagem } \\
\text { de CRM. 2. A principal vantagem deste tipo de aplicação é um contato regular } \\
\text { com o cliente, transferência sistemática de informações dentro da instituição, } \\
\text { controlo constante do progresso dos clientes e da sua atitude face ao treino, bem } \\
\text { como controlo da frequência de idas ao clube. } 3 \text {. As funções das ferramentas } \\
\text { apresentadas ajudam a gerir o centro de fitness, sendo algumas opções } \\
\text { voluntárias para o sócio. } 4 \text {. Os dados organizados corretamente podem ser uma } \\
\text { fonte rica de informações sobre as necessidades, hábitos, frequência treino, tipo } \\
\text { de atividade preferida, caráter de motivação, objetivos etc. }\end{array}$} \\
\hline $\begin{array}{l}\text { Customer Relationship } \\
\text { Management In A Fitness Club - } \\
\text { Case Study Of It Solutions Applied } \\
\text { In A Selected Organization. }\end{array}$ & & & \\
\hline $\begin{array}{l}\text { Gocłowska, S.; Piątkowska, M.; } \\
\text { Lenartowicz, M. } 2019 .\end{array}$ & \multirow{2}{*}{$\begin{array}{l}\text { Apresentar a } \\
\text { metodologia de } \\
\text { design e uso do CSI } \\
\text { (Customer Satisfaction } \\
\text { Index) para empresas } \\
\text { que prestam serviços } \\
\text { de fitness. }\end{array}$} & \multirow{2}{*}{$\begin{array}{l}76 \text { por } \\
\text { entrevista. } \\
\text { Polónia. }\end{array}$} & \multirow{2}{*}{$\begin{array}{l}\text { 1. Foco mais forte das empresas nas áreas que provaram ser pontos fracos e } \\
\text { ameaças em termos de nível de satisfação do sócio do fitness club: a localização, } \\
\text { o preço e as atividades promocionais do fitness club. } 2 \text {. A metodologia de } \\
\text { medição da satisfação do sócio parece estar adaptada à natureza dos sócios do } \\
\text { setor de fitness, bem como às pequenas e médias empresas que dominam nesse } \\
\text { campo. 3. Medir a satisfação do cliente torna possível tomar decisões e contribuir } \\
\text { para a qualidade dos serviços oferecidos. }\end{array}$} \\
\hline $\begin{array}{l}\text { Customer satisfaction and its } \\
\text { measurement in fitness clubs of } \\
\text { Warsaw. }\end{array}$ & & & \\
\hline $\begin{array}{l}\text { Giudicati, G.; Riccaboni, M.; Romiti, } \\
\text { A. } 2013 .\end{array}$ & \multirow[b]{2}{*}{$\begin{array}{l}\text { Analisar efeitos da } \\
\text { posse, contrato de } \\
\text { uso e socialização na } \\
\text { retenção de clientes. }\end{array}$} & \multirow{2}{*}{$\begin{array}{l}4.649 \text { sócios, } \\
133.945 \\
\text { registros de } \\
\text { inscrição } \\
\text { e } 4.892 \\
\text { contratos. } \\
\text { Itália. }\end{array}$} & \multirow{2}{*}{$\begin{array}{l}\text { 1. Clientes de longa data têm uma menor hipótese de renovar o contrato. } 2 \text {. A } \\
\text { centralidade do consumidor na rede reduz a taxa de rotatividade do cliente. } 3 \text {. A } \\
\text { inclusão de efeitos sociais aumenta o poder preditivo do modelo de rotatividade } \\
\text { do cliente. } \\
\text { 4. Os resultados deste estudo revelam de que modo os gestores podem } \\
\text { aproveitar as informações geradas por RFID para melhorar a satisfação e o } \\
\text { compromisso do cliente. }\end{array}$} \\
\hline $\begin{array}{l}\text { Experience, socialization and } \\
\text { customer retention: Lessons from } \\
\text { the dance floor. }\end{array}$ & & & \\
\hline
\end{tabular}

Continua na próxima página...

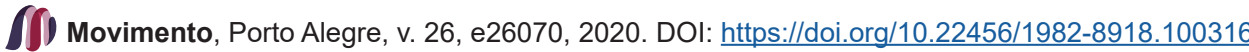


Continuação do quadro 3

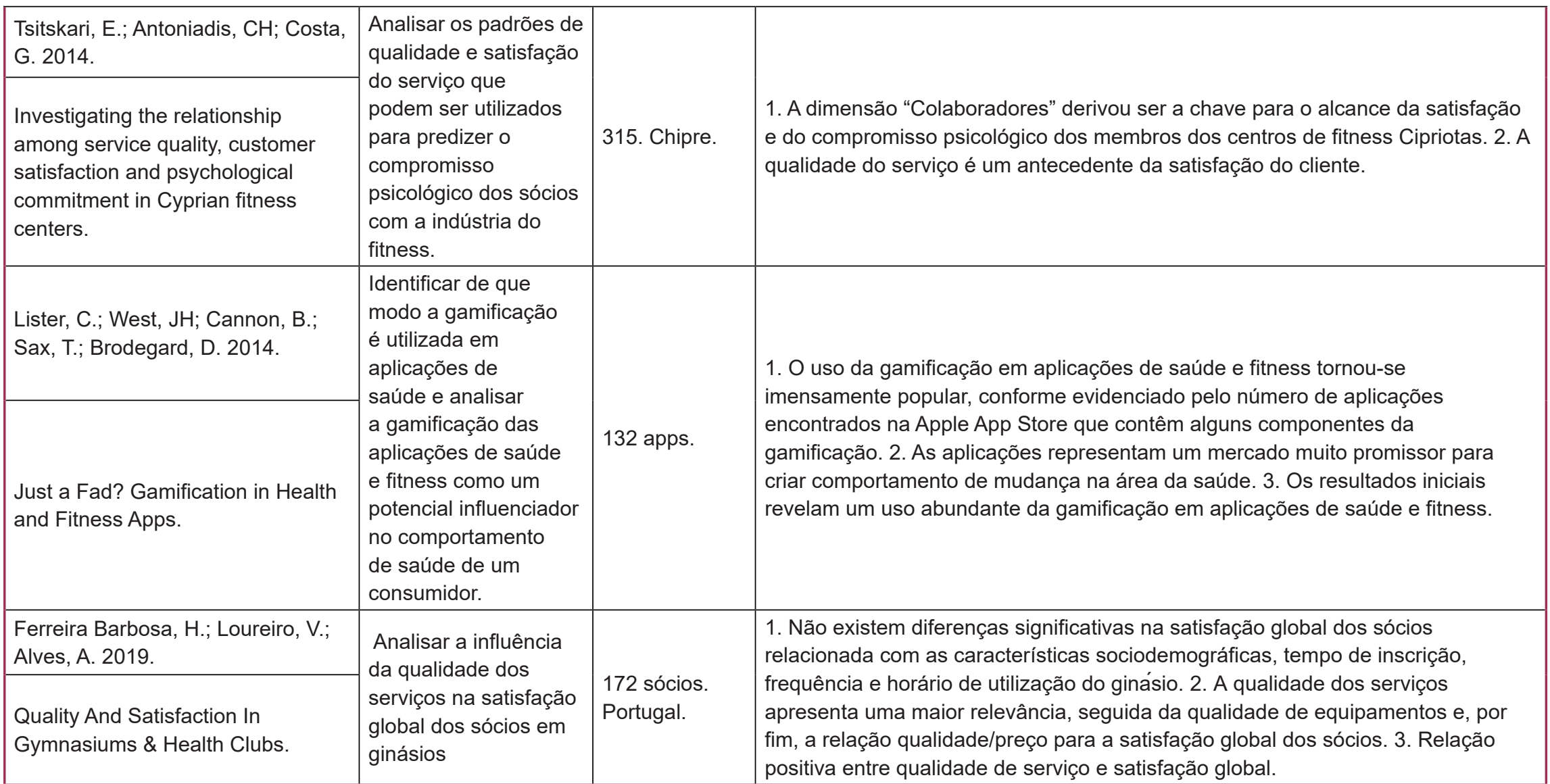

Fonte: Autores.

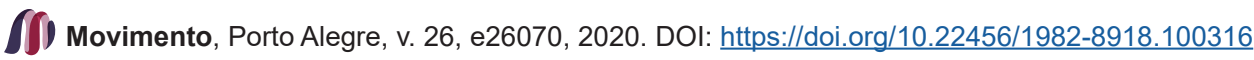


Abstract: The purpose of this systematic review is to identify the influence of social media and technologies on customer retention in gyms. The survey was conducted on four online databases from 2011 to 2019. Ten articles were selected through the PRISMA method (MOHER et al., 2009). The results showed that social media and the use of technologies are crucial in the retention process. After analyzing the ten articles, we also identified and analyzed the variables 'personal characteristic of members,' 'attendance and time of use,' 'quality of service and satisfaction' as influencing customer retention. In summary, this study reviewed the articles that study the impact of technologies and social networks on customer retention by gyms and helped to identify other factors that focus on retention, grouping them into two dimensions associated with the company and customers.

Keywords: Social Media. Technology. Behavior. Systematic Review.

Resumen: El objetivo de esta revisión sistemática es identificar la influencia de las redes sociales y las tecnologías en la retención de clientes en gimnasios. La investigación se llevó a cabo en cuatro bases de datos on-line, de 2011 a 2019. A través del método PRISMA (MOHER et al., 2009), se seleccionaron diez artículos. Los resultados mostraron que las redes sociales y el uso de tecnologías son fundamentales en el proceso de retención. Después de analizar los diez artículos, también se identificaron y analizaron las variables características personales de los socios, frecuencia y tiempo de uso, calidad del servicio y satisfacción, como elementos que influyen en la retención de clientes. En resumen, este estudio revisó los artículos que estudian el impacto de las tecnologías y las redes sociales en la retención de clientes en los gimnasios y ayudó a identificar otros factores que inciden en la retención de clientes, agrupándolos en dos dimensiones, empresa y cliente.

Palabras clave: Red Social. Tecnología. Comportamiento. Revisión Sistemática. 


\section{LICENÇA DE USO}

Este é um artigo publicado em acesso aberto (Open Access) sob a licença Creative Commons Atribuição 4.0 Internacional (CC BY 4.0), que permite uso, distribuição e reprodução em qualquer meio, desde que o trabalho original seja corretamente citado. Mais informações em: http://creativecommons.org/licenses/by/4.0

\section{CONFLITO DE INTERESSES}

Os autores declaram que não há conflito de interesses neste trabalho.

\section{CONTRIBUIÇÕES DE AUTORIA}

Helena Ferreira Barbosa: concepção, delineamento, análise e interpretação dos dados, redação e revisão do artigo, aprovação final da versão a ser publicada.

Jerónimo García-Fernandez: análise e interpretação dos dados, revisão do artigo. Gabriel Cepeda Carrión: análise e interpretação dos dados, revisão do artigo. aprovação final da versão a ser publicada.

\section{FINANCIAMENTO}

O presente trabalho foi realizado sem qualquer apoio financeiro.

\section{COMO REFERENCIAR}

FERREIRA BARBOSA, Helena; GARCÍA-FERNANDEZ , Jerónimo; CEPEDA CARRIÓN, Gabriel. Influência das tecnologias na retenção de sócios em ginásios: revisão sistemática Movimento, v. 26, p. e 26070, jan./dez. 2020. Disponível em: https://seer.ufrgs.br/Movimento/article/view/100316. Acesso em: 19 set. 2020. DOI: https://doi.org/10.22456/1982-8918.100316

\section{RESPONSABILIDADE EDITORIAL}

Alex Branco Fraga*, Elisandro Schultz Wittizorecki ${ }^{*}$, Ivone Job*, Mauro Myskiw*, Raquel da Silveira*

*Universidade Federal do Rio Grande do Sul, Escola de Educação Física, Fisioterapia e Dança, Porto Alegre, RS, Brasil 